population will not benefit them. Envisaging how the effects of the population approach can be evaluated formally, in a way similar to evaluating the effects of the high risk approach, is also hard. The high risk approach lends itself easily to evaluation by randomised controlled trials; the effect of the intervention on the risk factor, whether blood pressure, cognitive function, or bone mineral density, is soon obvious in people with extreme values, and the ultimate clinical benefits of the intervention, if they exist, are soon apparent. Deciding whether lowering the risk of a whole population provides the expected benefits, however, is not really amenable to classical randomised trials. It would require a change in lifestyle for many, starting from birth, and the benefits would be reaped only decades later. Definitive proof might always remain elusive. This is a plea not for complacency or fatalism but for a creative use of data from observational studies. The generation after Pickering and Rose has its work cut out.

Rose has carefully collected evidence to support his major theme. Still, the case for the population approach is not made naively as was sometimes done by the sanitary physicians in the past century and by early chronic disease epidemiologists in this one. People, and even their governments, retain the right to be foolish - the choice is theirs. Experts are gravely cautioned not to confound scientific results with personal prejudice. Also, the clinical or high risk approach is not despised as Rose is firmly convinced that you should not criticise a measure for what it fails to do but appreciate it for what it can do.

The Strategy of Preventive Medicine is the legacy of a life spent in the pursuit of better health for populations. The book exemplifies the humility of its acknowledgement, which, in effect, states that the thoughts of one person are only the modifications of the thoughts of a great many others. Rose does not shrink from controversy or self scrutiny. The book deserves to be read by all who care either for individual people or for populations. They will be confronted by some extremely clear thinking on crucially important topics.

A HOFMAN

Professor of Epidemiology

Erasmus University,

Rotterdam,

The Netherlands

J P VANDENBROUCKE

Leiden University,

Leiden,

The Netherlands

1 Rose G. The strategy of preventive medicine. Oxford: Oxford University Press, 1992

2 Swales JD, ed. Platt versus Pickering. An episode in recent medical history. London: Keynes Press, 1985.

\title{
The ups and down of bungee jumping
}

\section{Check the rope; forget the intravenous line}

In bungee jumping one end of an elastic rope is attached to the feet of someone prepared to jump from a great height - for example, a platform, bridge, or crane. The other end is made firm at the jumping off point. When the rope reaches its elastic limit the downward plunge is translated into an upward motion, returning the jumper almost, but not quite, to the jumping off point. The jumper oscillates to and fro until finally coming to rest. The sport is not new. Over 20 years ago David Attenborough recorded the initiation rites of some Pacific islanders, which required initiates to leap well over $30 \mathrm{~m}$ from a bamboo platform. To their legs was attached not a bungee rope but a length of vine. Each man was accompanied by a seconder, who encouraged his charge to jump by flaying his torso with a venomous plant.

Bungee jumping's increasing popularity raises two questions: why do people do it, and is it safe? Presumably people do it because it is very exciting - a "charge" lasting several days has been claimed to follow a single jump. Attempts have been made to see whether any hormonal changes might explain this elevation of mood.

In one study an experienced bungee jumper made several descents while hooked up to an intravenous line. Concentrations of $\beta$ endorphin, growth hormone, prolactin, testosterone, and follicle stimulating hormone did not change. ${ }^{1}$ But the results might have been different had the subject been an innocent bystander, pounced on and hurled from the jumping platform without warning. ${ }^{2}$

Feelings of exhilaration and wellbeing, often lasting several hours, are common after the stress of intense exercise. Few hormonal changes, however, are consistently found in athletes-whether recreational or Olympic class-after exercise. They are limited to a rise in plasma cortisol concentration and a small fall in testosterone concentration. ${ }^{3+}$ There must surely be some changes in neurotransmitter concentrations in the brain, but these are unlikely to be detectable in peripheral blood.

Undoubtedly, bungee jumping can be dangerous, although whether the sport should be blamed for the death of a fairground worker who forgot to attach his rope to anything is doubtful. ${ }^{5}$ Lethal accidents, however, have occurred after miscalculations of the extent to which the rope will stretch.

But the dangers of other sports should not be forgottenmountaineering and motor racing come immediately to mind. For these sports, however, the risks are tempered by a measure of skill. With bungee jumping there are no skills, and unless the total number of jumps made is known, estimation of the risks of a single jump is not possible. Apart from death nothing more serious than periorbital bruising has been reported.

So far, those taking part have usually been young, willing, and able, but now that bungee jumps are being performed for charity other people, who may not be so well prepared, will inevitably be drawn in. The crop of injuries resulting from stunts performed for charity such as parachute jumping should make us cautious. Who will decide whether a person is fit to participate and on what grounds? And who will bear the responsibility when things go wrong?

\section{MARK HARRIES}

Consultant Physician,

Northwick Park Hospital,

Harrow HAl 3UJ

1 Zimmerman U, Loew T, Wildt L. "Stress hormones" and bungee-jumping. Lancet 1992;340 428.

Vandenbroucke JP. Bungee-jumping and design of experiments. Lancet 1992;340:800.

Wheeler GD, Wall SR, Belcastro AN, Cumming DC. Reduced serum testosterone and prolectin levels in male distance runners. FAMA 1984;252:514-6.

4 Bullen BA, Skrinar GS, Beintins IZ, Cass DB, Reppert SM, Dotson CO, et al. Endurance training effects on plasma hormone responsiveness and sex hormone excretion. $\mathcal{F}$ Appl Physio 1984;56:1453-63.

5 Loose end kills bungee jumper. Today 1992; Aug 3. 